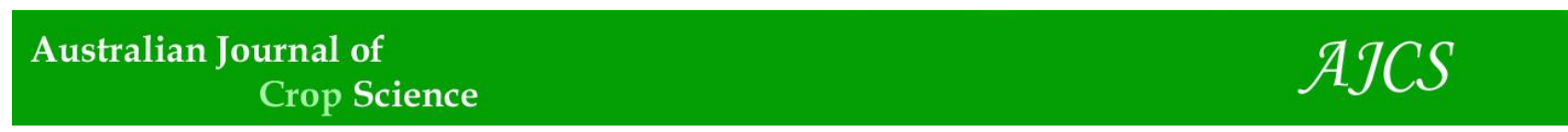

AJCS 11(07):799-805 (2017)

ISSN:1835-2707

doi: 10.21475/ajcs.17.11.07.pne383

\title{
Precision agriculture applied to soybean: Part III - Spatial and temporal variability of yield
}

\author{
Eduardo Leonel Bottega ${ }^{1}$, Daniel Marçal de Queiroz $^{2}$, Francisco de Assis de Carvalho Pinto ${ }^{2}$, \\ Domingos Sárvio Magalhães Valente ${ }^{2}$, Cristiano Márcio Alves de Souza ${ }^{3}$ \\ ${ }^{1}$ Federal University of Santa Maria, Cachoeira do Sul city, Rio Grande do Sul State, Brazil \\ ${ }^{2}$ Federal University of Viçosa, Agricultural Engineering Department, Viçosa city, Minas Gerais State, Brazil \\ ${ }^{3}$ Federal University of Grande Dourados, Faculty of Agricultural Sciences, Dourados City, Mato Grosso do Sul \\ State, Brazil
}

*Corresponding author: bottega.elb@gmail.com

\begin{abstract}
The Brazilian Savannah is an important production center of grains despite the presence of low fertility soils. In this agricultural scenario, the delineation of management zones for the application of lime and fertilizer seems to be promising for a high potential for success and may result in the reduction in production cost with an increase in the yield. The objective of this work was to evaluate the spatial and temporal variations in soybean yield in the Brazilian Savannah involving the delineation of management zones based on the apparent soil electrical conductivity (ECa). In an agricultural field in the Brazilian Savannah, 160 sampling points were taken as the references for the mapping of soybean yield in the crop seasons of 2011/2012, 2012/2013, and 2013/2014. In 2012/2013 and 2013/2014, the soil fertility was managed according to the classes set on the basis of measurement of ECa in 2012. The fertilizers were prescribed on the basis of soil sampling in each class. The class management resulted in an increase in the yield of each area. Over the three years of study, $1.2 \%$ of the area reported an unstable yield (with a coefficient of variation greater than 30 ). This low inconsistency may be attributed to the prediction error (the difference between predicted yield values and actual values) in nonsampled sites. The regulation of soil fertility using the management zones based on the apparent soil electrical conductivity is likely to reduce the spatial variability of the yield in the study area.
\end{abstract}

Keywords: Glycine max, site-specific management, apparent soil electrical conductivity, Oxisol.

\section{Introduction}

The region of the Brazilian Savannah stands out in national grain production despite the presence of low fertility soils. The productive fields of the region require the use of large amounts of fertilizers, making them a critical component of the production cost. Under this agricultural scenario, a potential technique for the regulation of spatial variability of crop and soil is to delineate the management zones to achieve soil conservation (Dalchiavon et al., 2012).

According to Rodrigues Junior et al. (2011), a management zone is defined as a sub-region of a field that has the same combination of production limiting factors such as yield and quality. Each management zone receives a specified dose of lime and fertilizers according to its characteristics (Fu et al., 2010). In this scenario, the apparent electrical conductivity of the soil has been demonstrated to be a reliable tool with a high potential for precision agriculture (Moral et al., 2010; Rodriguez-Perez et al., 2011) due to its low cost and quick measurement. In addition, it correlates well with the physical, chemical, and physicochemical characteristics of the soil that affect the crop yield.

The variation in yield not only reflects the change in the productive potential of a given area (Brock et al., 2005) but also indicates whether the management practices adopted have generated the expected results. Studies have reported a less variability in the yield in the areas where site-specific management was applied (Milani et al., 2006). Nevertheless, the variability in yield should be characterized by analyzing at least three yield maps (Santi, 2007). Blackmore et al.
(2003) noted that assessing the variability in yield requires the monitoring and analysis of a sequence of crop yield maps that allow the determination of the pattern of spatio-temporal variability of the area.

Yield mapping is an important tool for the management of precision farming systems since it allows evaluating whether the adopted decisions are reflected as positive effects on agricultural production. The current challenge is to manage the soil fertility to exploit the maximum productive potential of the crop, which is not uniform in the same field. In this context, class management is a promising tool for precision agriculture. Based on the previous studies, the objective of this work was to evaluate the temporal and spatial behavior of soybean yield in an area of the Brazilian savannah that was regulated using management zones delimited by the apparent electrical conductivity of the soil.

\section{Results and Discussion}

\section{Rainfall distribution in the study area}

Fig. 1 illustrates the distribution of rainfall in the study area for the three crop seasons. In the 2013/2014 crop season, the study area received less rainfall in November and December, when the crop was in the reproductive stage - the most critical period for yield. According to Embrapa (2011), the water requirement of soybean crops increases with the development of the plants, reaching their maximum during 
Table 1. Descriptive statistics of the soybean yield $\left(\mathrm{kg} \mathrm{ha}^{-1}\right)$ for the three crop seasons and for the average.

\begin{tabular}{lllll}
\hline \multirow{2}{*}{ Statistical parameters } & \multicolumn{3}{c}{ Crop seasons } \\
\cline { 2 - 5 } & $2011 / 2012$ & $2012 / 2013$ & $2013 / 2014$ & Average \\
\hline Mean & $2,302.75$ & $2,901.01$ & $2,530.19$ & $2,577.99$ \\
Median & $2,345.26$ & $2,925.54$ & $2,524.89$ & $2,581.40$ \\
Minimum & $1,225.06$ & $2,072.25$ & $2,155.01$ & $2,084.26$ \\
Maximum & $3,244.49$ & $3,342.39$ & $3,125.38$ & $2,978.03$ \\
$\sigma^{1}$ & 298.44 & 208.11 & 200.89 & 126.27 \\
$\mathrm{CV}(\%)^{2}$ & 12.96 & 7.17 & 7.94 & 4.90 \\
Lower quartile & $2,079.74$ & $2,802.79$ & $2,367.46$ & $2,500.74$ \\
Upper quartile & $2,498.20$ & $3,028.61$ & $2,681.97$ & $2,655.16$ \\
\hline
\end{tabular}

${ }^{1}$ Standard Deviation; ${ }^{2}$ Coefficient of Variation.

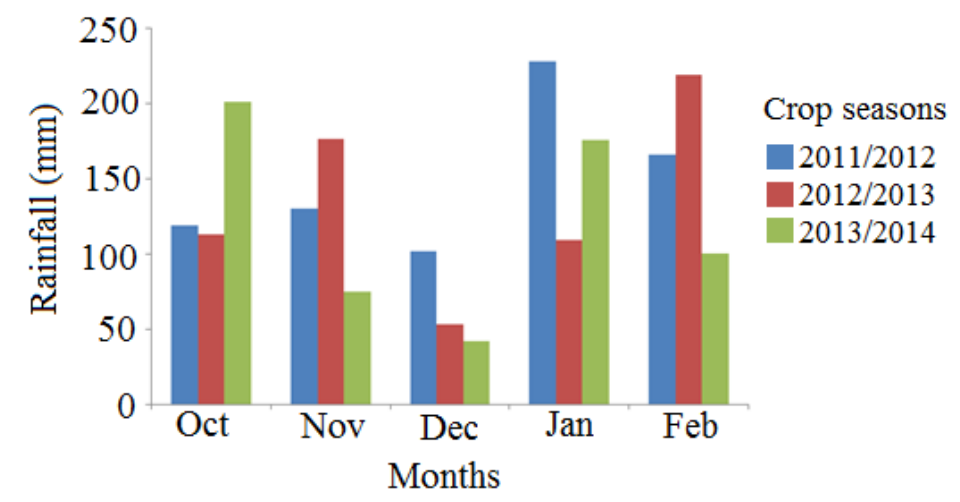

Fig 1. Rainfall distribution in the study area during the three crop seasons. The data was obtained from a pluviometer installed in the study area.

Table 2. Parameters of the theoretical semivariograms and cross-validation analysis for the models of the spatial dependence of the soybean yield for the three crop seasons.

\begin{tabular}{|c|c|c|c|c|c|c|}
\hline \multirow{2}{*}{ Crop Seasons } & \multicolumn{6}{|c|}{ Geostatistical parameters } \\
\hline & Model & $\mathrm{a}^{(1)}$ & $\mathrm{C}_{0}+\mathrm{C}^{(2)}$ & $\mathrm{C}_{0}^{(3)}$ & $\mathrm{RSS}^{(4)}$ & $\mathrm{R}^{2(5)}$ \\
\hline $2011 / 2012$ & Spherical & 373 & 0.90 & 0.001 & 7.01 & 0.95 \\
\hline $2012 / 2013$ & Exponential & 125 & 0.92 & 0.002 & 6.59 & 0.82 \\
\hline \multirow[t]{3}{*}{$2013 / 2014$} & Spherical & 272 & 0.85 & 0.002 & 8.24 & 0.87 \\
\hline & \multicolumn{6}{|c|}{ Parameters of cross-validation analysis } \\
\hline & \multicolumn{2}{|c|}{ Regression Coefficient } & \multicolumn{2}{|c|}{$\mathrm{Y}^{(6)}$} & $\mathrm{PES}^{(7)}$ & $\mathrm{R}^{2}$ \\
\hline $2011 / 2012$ & \multicolumn{2}{|c|}{1.00} & \multicolumn{2}{|c|}{-2.81} & 141.08 & 0.78 \\
\hline $2012 / 2013$ & \multicolumn{2}{|c|}{1.18} & \multicolumn{2}{|c|}{-522.16} & 96.21 & 0.79 \\
\hline $2013 / 2014$ & \multicolumn{2}{|c|}{1.06} & \multicolumn{2}{|c|}{-155.19} & 51.11 & 0.94 \\
\hline
\end{tabular}

${ }^{1}$ Range $(\mathrm{m}) ;{ }^{2}$ Sill; ${ }^{3}$ Nugget Effect; ${ }^{4}$ Residual Sum of Squares; ${ }^{5}$ Coefficient of Determination; ${ }^{6}$ Intercept; ${ }^{7}$ Prediction Standard Error.

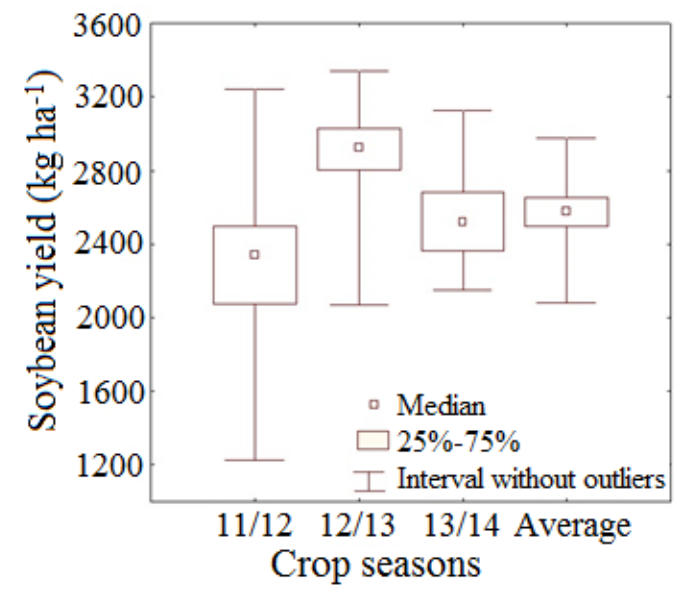

Fig 2. Soybean yield for each of the three crop seasons and their average yield. 
Table 3. The dose of the fertilizer* in $\mathrm{kg} \mathrm{ha}^{-1}$ used in the three crop seasons.

\begin{tabular}{lcc}
\hline Crop season & Management zone 1 & Management zone 2 \\
\hline $2011 / 2012 * *$ & 350 & 320 \\
$2012 / 2013$ & 380 & 300 \\
$2013 / 2014$ & 350 &
\end{tabular}

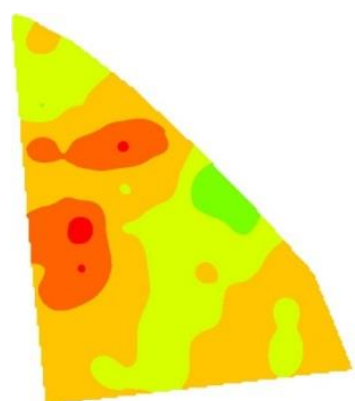

$2011 / 2012^{*}$

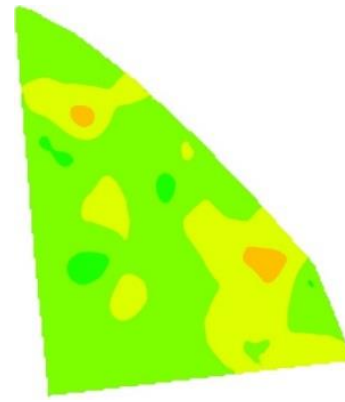

$2012 / 2013 * *$

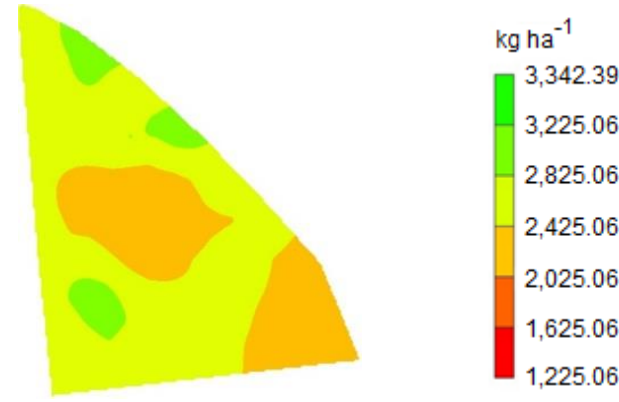

$2013 / 2014 * *$

Fig 3. Spatial variability of soybean yield for the three crop seasons. *Conventional management; **Management zone applied.

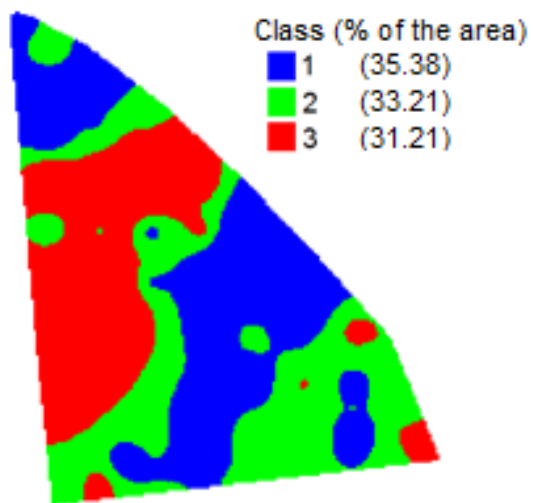

$2011 / 2012^{*}$

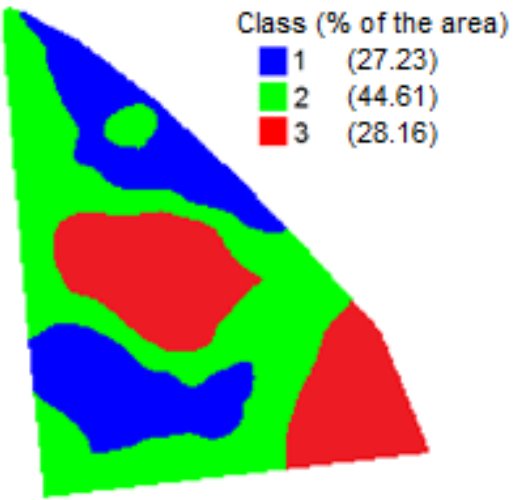

2013/2014**

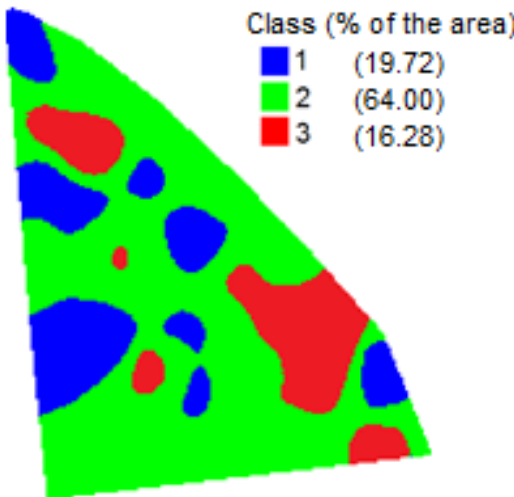

$2012 / 2013 * *$

Fig 4. Yield classification for each crop season and the average of the three seasons. Class 1: High and stable yield; Class 2: Moderate and stable yield; Class 3: Low and stable yield. * Conventional management; **Management zones applied. 


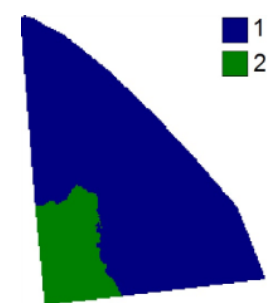

Fig 5. Delineation of two management zones (1 and 2) suggested by the zone map generated using soil ECa data.

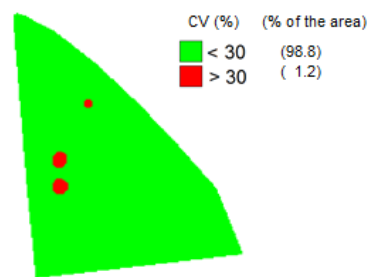

Fig 6. Classification of the coefficient of variation for yield in the three crop seasons. Stable yield: CV\% < 30 ; Unstable yield: CV\% $>30$.

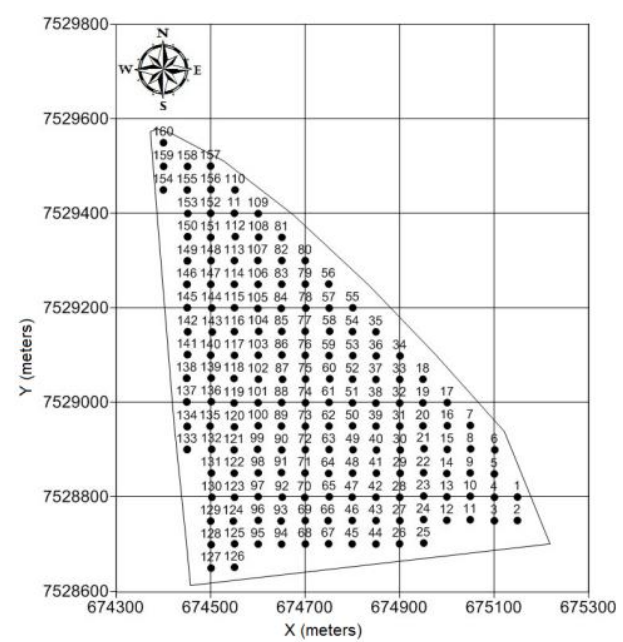

Fig 7. Representative map of the study area and the 160 sampling points used as a reference for the data collection. UTM Coordinates, Zone 21 South, datum SIRGAS2000.

the flowering and grain filling phases $\left(7-8 \mathrm{~mm} \mathrm{day}^{-1}\right)$. Lower rainfall during these developmental stages may cause an early fall of leaves and flowers, and abortion of pods ultimately resulting in a reduced grain yield.

\section{Soybean yield statistical analysis}

Table 1 presents the statistical analysis parameters of the yield data. The lowest average yield was obtained in the 2011/2012 crop season and the highest in 2012/2013. Although the 2013/2014 crop season received the least rainfall at the stage when the crop needs maximum water (the reproductive stage), the average yield was higher than that in the 2011/2012 crop season when the rainfall in the reproductive stage (December) was the highest (Fig 1). The minimum yield increased over the crop seasons, with the lowest value $\left(1,225.06 \mathrm{~kg} \mathrm{ha}^{-1}\right)$ recorded for the $2011 / 2012$ season and the highest $\left(2,155.01 \mathrm{~kg} \mathrm{ha}^{-1}\right)$ for the $2013 / 2014$ season. The standard deviation of the yield decreased from the first crop season to the last, indicating a reduced variation in the yield, which in turn suggests a reduction in the spatial variability of the yield.
The maximum coefficient of variation $(\mathrm{CV})$ for the studied crop seasons was $12.96(2011 / 2012)$, and the minimum was 7.17 (2012/2013). This interval was less than the CV calculated by Milani et al. (2006) and Amado et al. (2007).

Quartile values express the dispersion and central tendency of a data set. A lower quartile represents a value such that at least $25 \%$ of the data is not greater than it and at least $75 \%$ of the data is not less than it. Similarly, the upper quartile is a value such that at least $75 \%$ of the data is not greater than it and at least $25 \%$ of the data is not less than it. In this study, the values of the upper quartile for 2012/2013 until 2013/2014 were higher than those observed for 2011/2012. According to Amado et al. (2007), the interquartile range is less subjected to errors than the isolated values such as minimum and maximum yield.

The distribution of the soybean yield (box plot) for each of the three crop seasons and the average yield obtained from these three crop seasons are shown in Fig. 2. Outliers were not detected. For the 2011/2012 crop season, most of the sampling points exhibited a yield less than the median yield, which was not observed for the other studied seasons. The median value of soybean yield increased from 2011/2012 to $2012 / 2013$, with a slight decrease in 2013/2014; however, 
this median yield was greater than that observed for the first crop season (2011/2012). This decrease in the median value may be explained by the rainfall deficit during the reproductive stage of the crop in 2013/2014.

Another relevant result is related to the minimum yield registered in the study area for the three crop seasons. This value increased from one season to another, from $1225.06 \mathrm{~kg}$ $\mathrm{ha}^{-1}$ in the first crop season (uniform management) to $2155.01 \mathrm{~kg} \mathrm{ha}^{-1}$ in the final season (class management). These results strongly indicate that the use of ECa as a discriminating factor is promising for delineating the management zones for fertilizer application. Johnson et al. (2005) noted that the factors contributing to ECa also limit the yield, given the significant relationship between ECa and both soil attributes and crop yield. The authors concluded that $\mathrm{ECa}$ is an important tool that can be used to identify variability in the soil fertility.

\section{Soybean yield spatial variability}

Soybean yield was observed to be strongly spatially dependent, regardless of the studied crop season. The 2011/2012 crop season recorded the greatest range in the semivariogram. The semivariance model of this season had the greatest prediction standard error (PES) and the lowest coefficient of determination for the cross-validation analysis (Table 2).

The spatial distribution of the soybean yield for the three crop seasons studied is shown in Fig 3. The minimum yield during the three crop seasons and the greatest difference was observed between 2012/2013 and 2013/2014. The maximum soybean yield in $2012 / 2013$ was $2017.01 \mathrm{~kg} \mathrm{ha}^{-1}$, which was greater than the maximum yield obtained in 2013/2014. Although the maximum value fluctuated across the three years, the coefficient of variation of the maximum yield was low $(3.36 \%)$ compared with that of the minimum yield $(28.32 \%)$. This can be explained by the use of class management practices, in which a soil fertilizer was applied at the recommended varying rates to meet the needs of the soybean crop based on the soil fertility in each class.

The positive impact on the crop yield resulting from the adopting zone management was similar to that reported by other authors. Rodrigues et al. (2008) concluded that the adoption of management zone practices associated with the general concept of precision agriculture made possible the management of soil quality and resulted in increased yield, as also observed in this study. In addition to the yield gains, the present study demonstrated that the adoption of management zones increased the homogeneity thereby reducing the coefficient of variation from $12.96 \%$ in the first season to $7.94 \%$ in the last studied crop season.

For the 2011/2012 season, the soybean yield was practically categorized into equal proportions among the three classes (high and stable, moderate and stable, and low and stable). The percentage of the area with moderate yield increased from 2011/2012 to 2012/2013, where 64\% of the area was classified as having moderate yield. Overall, across the three crop seasons, $74.79 \%$ of the area obtained moderate yield, demonstrating a tendency towards the homogeneity of yield due to the class management. This trend was possibly diminished by the water deficit observed in 2013/2014, which directly influenced the soybean yield (Fig 4).

Essentially, the yield of the entire study area $(98.8 \%$ of the area) was stable, with a CV less than $30 \%$. Only $1.2 \%$ of the area had a CV greater than $30 \%$, indicating instability in soybean yield. These results are probably related to the fertilization management using the management zones, in which fertilizer recommendations are made considering the requirements of each area and not of the field as a whole (Fig 5).

Only $1.2 \%$ of the area had a yield with a CV greater than 30 classified as unstable (Fig 6). This value is considered to be a positive result because, in $98.8 \%$ of the area, the $\mathrm{CV}$ of the yield of each pixel of the map was less than $30 \%$. Bottega et al. (2013) investigated the spatial and temporal variability of the soybean yield in a no-tillage field with soil fertility management performed homogeneously and found that $12.7 \%$ of the study area had unstable yield. The authors emphasized that the analysis of temporal yield variability represents a tool with a high potential for studying areas with low yield.

Milani et al. (2006) also observed that areas with localized management displayed a greater homogeneity of yield. Another analysis demonstrated the regulation of soil fertility through management zones on the basis of apparent soil electrical conductivity with an aim to homogenize the yield of the area. It classified the yield according to the coefficient of variation $(\mathrm{CV})$ observed in each pixel of the map for several crop seasons (Molin, 2002) as stable or unstable, enabling the construction of thematic maps that reference instability sites.

The adoption of management zones for lime and fertilizer application has been used in precision agriculture systems to address variability in the soil. The use is justified by the significant reduction in the required number of soil samples, which depending on the sampling grid used, involves intensive use of labor for sampling and laboratory analysis, thus increasing the production cost (Zhang et al., 2010). The cost of sampling and analysis may cause the application of precision agriculture techniques to be unfeasible (McCormick et al., 2009).

The studies on the use of apparent soil electrical conductivity (ECa) in agriculture have been developed since 1920. Although such research is not new, Yan et al. (2007) highlighted the need for further research to determine the effectiveness of fertility management through site-specific management zones. This study analyzed the effect of management zones delineated on the basis of ECa of the soil for the application of fertilizers on soybean yield. The study was performed in a field located in the Brazilian Savannah. There was an increase in the average yield after adopting management zones from $2302.75 \mathrm{~kg} \mathrm{ha}^{-1}$ in 2011/2012 (uniform management of the field) to $2901.01 \mathrm{~kg} \mathrm{ha}^{-1}$ in $2012 / 2013$ and $2530.19 \mathrm{~kg} \mathrm{ha}^{-1}$ in 2013/2014 both using fertilizer recommendations made after soil sampling of the classes. In the latter crop season, the crop was subjected to drought stress in the most critical developmental stage, i.e., the reproductive stage.

\section{Materials and Methods}

\section{Study area description}

The study was conducted at the Sao Judas Tadeu Farm, in the municipality of Ponta Pora, Mato Grosso do Sul (22 32' 09', south latitude and $55^{\circ} 43^{\prime} 33^{\prime \prime}$ west longitude), Brazil. The farm has a total area of 450 ha for agriculture in which soybean (Glycine max) and corn (Zea mays) have been cultivated in a succession system using no-tillage for over 12 years. The area has an average altitude of 755 meters above sea level and is flat to gently undulating topography.

The soil is classified as a clayey Oxisol (Embrapa, 2006). According to the Koppen classification, the climate is Aw (subtropical) with an average annual temperature of $20.6{ }^{\circ} \mathrm{C}$. 
The average annual rainfall is $1,660 \mathrm{~mm}$ without a distinct dry period but with wetter summers. The rainiest month is November with an average rainfall of $212 \mathrm{~mm}$, whereas the driest month is July with an average rainfall of $55 \mathrm{~mm}$. The study was performed in a 47 ha field in which 160 sampling points were plotted as shown in Fig. 7.

\section{Experimental procedure}

The spatial variability of the soybean yield was examined for three crop seasons (2011/2012, 2012/2013, and 2013/2014) with the cultivar BMX Power RR. Soybean sowing was performed, respectively, on October 27, 13, and 15 for the first, second, and third crop seasons. As the farm did not have a grain yield monitor installed in the harvester, yield determination was performed manually. At each sampling point, soybean samples were taken to estimate the yield of the area and for the subsequent construction of yield maps for the 2011/2012, 2012/2013, and 2013/2014 crop seasons.

Three, one-meter rows totaling an area of $1.35 \mathrm{~m}^{2}$ per sampling point were harvested at a density equivalent to 3.4 points per hectare. Samples were manually processed (threshed and cleaned). For each sample, the moisture content was determined using a capacitance method moisture meter. The samples were weighed using a precision balance, the obtained weight was corrected for $13 \%$ moisture, and the yield was expressed in $\mathrm{kg} \mathrm{ha}^{-1}$.

\section{Statistical analysis}

The yield values of each sampling point (Fig 7) for the studied crop season comprised the database used for analyses. At first, the data were analyzed using descriptive statistics to characterize the yield of each year. Later, geostatistical analysis characterized the spatial dependence of the soybean yield for each year.

The spatial dependence was evaluated by variogram fitting, assuming the stationarity of the intrinsic hypothesis, and using Equation 1.

$\hat{\gamma}(h)=\frac{1}{2 N(h)} \sum_{i=1}^{N(h)}\left[Z\left(x_{i}\right)-Z\left(x_{i+h}\right)\right]^{2}$

where,

$\hat{\gamma}(h)=$ Semivariance as a function of the distance $(\mathrm{h})$ between pairs of points;

$\mathrm{h}=$ Distance between pairs of points, $\mathrm{m}$;

$\mathrm{N}(\mathrm{h})=$ Number of experimental pairs of observations $\mathrm{Z}\left(\mathrm{x}_{\mathrm{i}}\right)$ and $\mathrm{Z}\left(\mathrm{x}_{\mathrm{i}+\mathrm{h}}\right)$ separated by a distance $\mathrm{h}$.

The following variogram models were tested: linear with sill, Gaussian, spherical, and exponential. The model resulting in the lowest residual sum of squares (RSS) was selected, followed by the determination of following parameters: nugget effect $\left(\mathrm{C}_{0}\right)$, contribution $(\mathrm{C})$, sill $\left(\mathrm{C}_{0}+\mathrm{C}\right)$, and range (A).

Once the spatial dependence was detected, the thematic map of the spatial variability of the attribute was generated. The interpolation of the maps was performed using ordinary kriging variogram. To estimate the values in non-sampled locations, 16 closest neighbors were used with a neighborhood radius equal to the range value found in the variogram fitting. All interpolated maps consisted of a $5 \times 5$ meter square grid.

\section{Yield classification map}

After the spatial dependence analysis, maps for soybean yield classification (high, moderate, and low) were constructed for the three crop seasons and the temporal variability of the yield of each point on the grid (stable or unstable). For these maps, the criteria listed below were used, as proposed by Molin (2002):

a) Yield greater than $105 \%$ of the field average and coefficient of variation (CV) less than $30 \%$ (high and stable yield);

b) Yield between $95 \%$ and $105 \%$ of the field average and CV less than $30 \%$ (moderate and stable yield);

c) Yield less than $95 \%$ of the field average and CV less than $30 \%$ (low and stable yield);

d) Yield with CV greater than $30 \%$ (unstable yield).

\section{Soil fertility management}

Until the mapping of the first crop season, 2011/2012, the field was managed using the uniform dosage of inputs with the application of fixed levels of fertilizers throughout the area. In 2012, after the harvest, the apparent soil electrical conductivity (ECa) was mapped for the delineation of management zones. A management zone is defined as a subregion of a field that has the same combination of limiting factors of productivity and quality for which a uniform dose of inputs can be applied (Rodrigues Junior et al., 2011).

To map soil ECa, a portable device, the Landviser ${ }^{\circledR}$ LandMapper ${ }^{\circledR}$ ERM-02 was used. ECa was determined using four equally spaced electrodes ( 0.20 meters $)$ in a Wenner matrix arrangement (Corwin and Lesh, 2003). Electric current was applied to the external electrodes, and the potential difference between the internal electrodes was recorded in the memory for a later definition of management classes.

The definition of management classes was performed using KRIG-ME software developed by Valente (2010), which uses the fuzzy k-means classification algorithm. The number of management zones that best represent the data cluster was defined as a function of the fuzziness performance index (FPI), which estimates the degree of separation of members into different classes, and the modified partition entropy (MPE), which estimates the degree of disorganization created by the number of zones. These indices range between 0 and 1 , and the optimal number of management zones is obtained when both indices are minimized (Song et al., 2009). Fig 7 shows the class map adopted for soil fertility management for the subsequent crop seasons (2012/2013 and 2013/2014).

Table 3 lists the doses of fertilizers used in the crop planting. In 2011/2012, the dose applied was homogeneous for the whole area, whereas in the subsequent crop seasons, fertilizers were applied at different doses as prescribed considering the soil analysis of each management zone.

\section{Software used}

The descriptive statistical analysis was performed using Statistica 7. The geostatistical analysis was performed using GS+ 9. For the preparation of the maps, KRIG-ME software (Valente, 2010) was used.

\section{Conclusion}

The class management resulted in an increase in the soybean yield of the area. Over the three crop seasons evaluated, $1.2 \%$ of the area demonstrated an unstable yield $(\mathrm{CV}>30 \%)$. The 
regulation of soil fertility using management zones based on the apparent soil electrical conductivity is likely to reduce the spatial variability in the yield in the study area.

\section{Acknowledgements}

The authors thank the National Council for Scientific and Technological Development (CNPq) and the Research Foundation of the State of Minas Gerais (FAPEMIG) for scholarships and financial support for the completion of this study and the São Judas Tadeu Farm for offering the study area and logistics demanded of this work

\section{References}

Amado, TJC, Pontelli CB, Santi AL, Viana JHM, Luciano Sulzbach LAS (2007) Variabilidade espacial e temporal da produtividade de culturas sob sistema plantio direto. Pesqui Agropecu Bras. 42(8):1101-1110.

Blackmore BS, Godwin RJ, Fountas S (2003) The analysis of spatial and temporal trends in yield map data over six years. Biosys Eng. 84(4):455-466.

Bottega EL, Pinto FAC, Queiroz DM, Santos NT, Souza CMA (2013) Variabilidade espacial e temporal da produtividade de soja no Cerrado brasileiro. Rev Agrarian. 6(20):167-177.

Brock A, Brouder SM, Blumhoff G, Hofmann BS (2005) Defining yield-based management zones for corn-soybean rotations. Agron J. 97(4):1115-1128.

Corwin DL, Lesch SM (2003) Application of Soil Electrical Conductivity to Precision Agriculture: Theory, Principles, and Guidelines. Agron J. 95(3):471-471.

Dalchiavon FC, Carvalho MP, Andreotti M, Montanari R (2012) Variabilidade espacial de atributos da fertilidade de um Latossolo Vermelho Distroférrico sob Sistema Plantio Direto. Rev Cienc Agron. 43(3):453-461.

EMBRAPA (Empresa Brasileira de Pesquisa Agropecuária) (2006) Sistema brasileiro de classificação de solos, 2nd edn. Rio de Janeiro: EMBRAPA-SPI, 306 p.

EMBRAPA (Empresa Brasileira de Pesquisa Agropecuária) (2011) Tecnologias de produção de soja na região central do Brasil. Londrina: Embrapa Soja, 261 p.

Fu Q, Wang Z, Qiuxiang J (2010) Delineating soil nutrient management zones based on fuzzy clustering optimized by PSO. Math Comput Model. 51(11-12):1299-1305.

Johnson C, Eskridge K, Corwin D (2005) Apparent soil electrical conductivity: applications for designing and evaluating field-scale experiments. Comput Electron Agr. 46:181-202.

McCormick S, Jordan C, Bailey J (2009) Within and between-field spatial variation in soil phosphorus in permanent grassland. Precis Agric. 10(3):262-276.
Milani L, Souza EG, Uribe-Opazo MA, Gabriel Filho A, Johann JA, Pereira JO (2006) Unidades de manejo a partir de dados de produtividade. Acta Sci Agron. 28(4):591-598.

Molin, JP (2002) Definição de Unidades de manejo a partir de mapas de Produtividade. Eng Agric. 22:83-92.

Moral FJ, Terrón JM, Silva JRM (2010) Delineation of management zones using mobile measurements of soil apparent electrical conductivity and multivariate geostatistical techniques. Soil Till Res. 106(2):335-343.

Rodrigues GS, Buschinelli CC, Santana DP, Silva AG, Pastrello BMC (2008) Avaliação ambiental de práticas de manejo sítio específico aplicadas à produção de grãos na região de Rio Verde (GO). Rev Bras Agrocien. 14(3-4):5866.

Rodrigues Junior FA, Vieira LB, Queiroz DM, Santos NT (2011) Geração de zonas de manejo para cafeicultura empregando-se sensor SPAD e análise foliar. Rev Bras Eng Agric Amb. 15(8):778-787.

Rodríguez-Pérez JR, Plant RE, Lambert JJ, Smart DR (2011) Using apparent soil electrical conductivity (ECa) to characterize vineyard soils of high clay content. Precis Agric. 12(6):775-794.

Santi AL (2007) Relações entre indicadores de qualidade do solo e a produtividade das culturas em áreas com agricultura de precisão. Tese (Doutorado em Ciência do Solo) - Centro de Ciências Rurais, Universidade Federal de Santa Maria, Santa Maria, 150p.

Song X, Wang J, Huang W, Liu L, Yan G, Pu R (2009) The delineation of agricultural management zones with high resolution remotely sensed data. Precis Agric. 10(6):471487.

Valente DSM (2010) Desenvolvimento de um sistema de apoio à decisão para definir zonas de manejo em cafeicultura de precisão. Tese (Doutorado em Engenharia Agrícola) - Departamento de Engenharia Agrícola, Universidade Federal de Viçosa, Viçosa, 122p.

Yan L, Zhou S, Feng L (2007) Delineation of site-specific management zones based on temporal and spatial variability of soil electrical conductivity. Soil Sci Soc China. Pedosphere. 17(2):156-164.

Zhang X, Shi L, Jia X, Seielstad G, Helgason C (2010) Zone mapping application for precision-farming: a decision support tool for variable rate application. Precis Agric. 11(2):103-114 